www.periodicos.unimontes.br/index.php/caminhosdahistoria

\title{
Resenha
}

Resenha do livro: CRUZ, Denise Rollemberg. Resistência: memória da ocupação nazista na França e na Itália. São Paulo: Ed. Alameda, 2016.

\section{AS RESISTÊNCIAS À HISTÓRIA NAS NARRATIVAS MUSEOLÓGICAS FRANCESAS E ITALIANAS}

\author{
Jougi Guimarães Yamashita ${ }^{1}$
}

É bastante perceptível o fascínio que a experiência nazifascista e a Segunda Guerra Mundial exercem no público - especializado ou não - de história no Brasil. Se os motivos para tal não cabem em uma resenha, vale ao menos mencionar que o amplo alcance tem seus bônus e ônus. Apesar de ser um contexto com ampla e consolidada bibliografia, em muitos espaços parecem persistir análises há muito relativizados pela historiografia acadêmica. Existe um claro embate narrativo que dificulta muito o estabelecimento desses discursos fora das universidades. E mesmo dentro delas.

É no sentido de contribuir para o rompimento dessa barreira que a obra Resistência: memória da ocupação nazista na França e Itália, fruto de pesquisa pós-doutoral de Denise Rollemberg da Cruz, se propõe a atuar. A autora, professora de História Contemporânea do Instituto de História e do programa de Pós-Graduação em História da Universidade Federal Fluminense (UFF), tem a carreira bastante associada aos estudos sobre a ditadura militar brasileira, mas há algum tempo dedica-se também ao contexto europeu, em particular sobre os regimes autoritários da primeira metade do século XX. Existe um diálogo teórico basilar entre os eventos históricos que muito parece ter auxiliado a autora em suas reflexões: tratam-se de experiências traumáticas, que expõem indivíduos a situações-limite e colocam em questionamento projetos políticos que veiculam ideias de harmonia social. Mais do que isso, a historiografia está constantemente empenhada em "mexer no vespeiro" desses eventos, tão embrenhados no debate das relações entre memória e história nos dias atuais. Se a Europa é

\footnotetext{
${ }^{1}$ Doutor pelo Programa de Pós-Graduação em História Social da Universidade Federal Fluminense (UFF). Professor do Ensino Fundamental da Escola Municipal Albert Einstein-RJ. E-mail: jougihist@gmail.com. ORCID: https://orcid.org/0000-0002-3686-4500
} 
palco privilegiado do livro, ficam evidentes também as marcas da trajetória pregressa da autora nas linhas que o compõem.

A aposta de Rollemberg está, então, em promover uma discussão conceitual e uma abordagem metodológica que dê conta de exibir, nos casos francês e italiano, uma mostra material dessa tensão mnemônica relativa à ocupação nazista, sobretudo a partir dos discursos museológicos produzidos pelos estados em questão, esmerados em cristalizar determinadas abordagens sobre os eventos históricos que dão nome às instituições. Desde a apresentação, ela já nos apresenta um importante diagnóstico: foi a partir da glorificação da Resistência que começaram a surgir museus e memoriais da mesma (p.12). Importa destacar que a obra não versa apenas sobre o museu: um capítulo é dedicado a escrita epistolar, e o último, ainda que reflita sobre um museu, tem como eixo os usos da memória sobre um evento ocorrido na Itália. Trata-se, portanto, das relações entre história e memória.

O livro é dividido em cinco capítulos. O Capítulo 1 dedica-se ao debate teórico relativo à conceituação de "Resistência"2. Nele, fica evidente a complexidade do problema. Em cada uma das realidades analisadas - França, Itália e Alemanha - há um debate particular, e a mesma dificuldade em encontrar uma definição hegemônica. A fluidez polissêmica é o tom da questão, sempre mediada por interesses políticos e disputas discursivas. Se cada caso é um, parece à autora que as décadas de 1970 e 1980 foram comumente decisivas no sentido de serem o marco das transformações sociais que terminaram por acarretar no pensar sobre as Resistências. Distância temporal, acesso aos arquivos, interesses de geração, enfim, inúmeras circunstâncias propiciaram essa evidente mudança que, ao fim e ao cabo, irá acirrar as tensões memorialísticas sobre os eventos.

$\mathrm{Na}$ competente discussão historiográfica trazida pela historiadora, fica evidente uma espécie de fórmula para o desenrolar da reflexão conceitual em cada país: quanto mais autoritário o regime, mais elástico o conceito parece se tornar - e assim abraçar uma variedade ainda maior de comportamentos. Assim, para os franceses resistir é agir diante de um inimigo externo. Com os italianos, o debate se aprofunda, uma vez que uma questão se impõe: a resistência teria se dado em relação a Mussolini (então, desde a década de 1920) ou no contexto da capitulação da Itália, da ocupação alemã e da República de Saló (1943)? E no

\footnotetext{
${ }^{2}$ A história dos conceitos, como sabemos, ganhou bastante corpo sobretudo a partir dos estudos de Reinhart Koselleck. Lembremos com o autor (mesmo que não tenha sido citado por Rollemberg) da ideia de que um conceito é também um ato - uma vez que colabora com uma prática ou ação no tempo histórico, e não apenas o nomeia. Isso fica muito claro com o conceito de Resistência.
} 
caso alemão, em que o país não foi invadido? Haveria espaço para resistir? O que seria resistir naquele contexto?

Há ainda outros imperativos que dialogam diretamente com cada realidade nacional. Por exemplo, aquilo que envolve a coletividade ou individualidade da agência. No caso francês, a ação é primariamente coletiva (ainda que algumas atitudes individuais sejam consideradas também atos de resistência), enquanto na Alemanha a individualidade se impõe. O mesmo contraste se observa em relação à legalidade: enquanto na França a ilegalidade é condição mandatória para o ato de resistir, na Alemanha os resistentes são encontrados dentro dos signos das leis de então (funcionários de Estado, generais e outros militares, por exemplo que, em suas atividades, conseguiram de alguma forma apoiar o combate ao nazismo). Aqui a escolha da autora em comparar as distintas experiências se mostra um grande acerto, pois fica evidente essa ocasionalidade que conforma o conceito. No Estado invadido pode haver essa associação com a coletividade porque essa - a princípio - é contrária à barbárie nazista ${ }^{3}$, enquanto no outro a resistência tem que ser individual porque a coletividade é o inimigo. $\mathrm{Na}$ primeira agir ilegalmente é enfrentar o autoritarismo; na segunda, é necessário buscar a partir da legalidade a prátia resistente.

À essa pequena amostra da complexidade do debate somamos as cores locais de cada caso analisado. O que cada autor (e fontes, nos capítulos seguintes) considera ser resistência. Isso também varia, e muito, ao longo do tempo e de acordo com as subjetividades e escolhas políticas. Rollemberg destaca a importância de trabalhos como os de Henri Michel na década de 1960 e de Robert Paxton na seguinte (p. 23-25) para promover o repensar sobre o papel da França e dos franceses na Segunda Guerra Mundial. Ao fim e ao cabo, a variante que torna a conceitualização de "resistência" tão difícil é justamente a vida humana, tão prenhe de inconsistências e desvios que marcam uma trajetória individual. Nas discussões analisadas pela historiadora, é crucial considerar o que Primo Levi chamou de "zona cinzenta", que escancara a insuficiência da oposição "resistente" versus "colaborador", como se somente existisse a possibilidade de ser um ou outro. O termo, como disse Levi em Os Afogados e os Sobreviventes (2004), refere-se a uma zona de contornos mal definidos, da qual bem e mal, culpa e inocência fundem-se nos comportamentos do campo, impedindo qualquer tentativa de racionalizar a experiência concentracionária. Extrapolar o uso do termo da experiência dos campos para as vivências em territórios ocupados ou governados pelos fascismos é, para essa

\footnotetext{
${ }^{3}$ É muito importante destacar que aqui pensamos dentro da perspectiva das narrativas construídas sobre os eventos e que foram centrais nas discussões conceituais sobre a "Resistência". Dizemos isso por conta da experiência colaboracionista francesa, encarnada na França de Vichy, que a autora também destaca e analisa em seu livro.
} 
historiografia, ser capaz de observar a multiplicidade de comportamentos e a imensa dificuldade em atingir o consenso. Rollemberg, nesse sentido, comenta que mais importante do que encontrar essa definição harmônica é observar justamente as tensões e limites do uso da palavra (p.67).

Importa, por fim, destacar nesse capítulo que a autora comenta também sobre outros conceitos que rodeiam o de resistência, como os de oposição, resiliência, dissensão, entre outros. Os tais múltiplos comportamentos que destacam a vida na zona cinzenta, repetimos, são difíceis de serem aceitos dentro das rédeas de uma definição.

Sem que esse debate se feche, ele ganha novos e intrincados contornos, quando confrontados diante da temporalidade e dos usos políticos do passado. Isso fica gritante ao final do capítulo, quando a historiadora nos atenta para uma importante tensão entre memória e história: há um evidente descolamento narrativo no que envolve a questão étnica e racial e a luta contra a extrema-direita nesse momento analisado. $\mathrm{O}$ aspecto racial dos fascismos não importava muito para a ação resistente ${ }^{4}$. Por outro lado, ele é crucial para o esforço de memória. Não foi o gatilho das resistências, mas é a tônica da lembrança sobre elas.

É com esse olhar que Rollemberg analisa os Museus e memoriais da Resistência no restante do livro. A parte 1, composta pelos capítulos 2 e 3, dedica-se ao caso francês. No capítulo 2, a autora enfoca um rico conjunto de cerca de 60 museus ao longo de todo o território nacional. Ao observar tão ampla gama de lugares de memória (e aqui devemos a Pierre Nora o aparato teórico para a discussão), a historiadora chega a algumas conclusões interessantes. Existem, é claro, especificidades para cada instituição, relativas a questões de acervo, iluminação, uso de som, recursos audiovisuais, a grandiloquência do local, a cenografia, entre outros aspectos. No entanto, também parece claro a ela um certo apego a determinados modelos. Charles de Gaulle e Jean Moulin, lideranças da Resistência (externa e interna) Francesa, são figuras onipresentes, que têm destacadas as suas ações heroicas durante o conflito, enquanto são deixados de lado aspectos que poderiam ser contraditórios (mesmo no Museu Jean Moulin, em Paris ${ }^{5}$.

Em termos narrativos, visualiza a repetição daqueles lugares comuns que apostam na cronologia mais simples para tratar da ascensão da extrema direita no período entreguerras até

\footnotetext{
${ }^{4} \mathrm{O}$ antissemitismo, por exemplo, não fazia parte dos discursos e práticas políticas de Mussolini na Itália. Na França, a maioria dos movimentos que compôs a M.U.R. (Movimentos Unidos da Resistência) não tinha a luta racial como pauta.

${ }^{5} \mathrm{Na}$ própria apresentação do livro a autora destaca a homossexualidade de Jean Moulin, que não aparece em nenhuma narrativa museológica, já que o grande mártir da Resistência não poderia, dentro de uma perspectiva conservadora de sociedade, estar associado a esse aspecto de sua intimidade. Lembremos também da problemática presidência de De Gaulle no contexto pós-guerra, entre 1959 e 1969.
} 
o estopim do conflito mundial e a experiência concentracionária. Há um certo apagamento das regionalidades de cada museu em nome dessa narrativa única e da função pedagógica que lhes cabem (p.125). A autora observa que existem poucos relatos de sobreviventes de campos de trabalho nos museus, e de nenhum relativo aos colaboradores. Ora, isso seria escancarar as inconsistências, a zona cinzenta, e a participação ativa do estado francês no genocídio (p.122). Um desserviço ao esforço de pacificação do passado proposto pelos museus.

Aqui apresenta-se o argumento mais forte desse capítulo, que é justamente a percepção de que há uma sobreposição da memória em relação à história nas narrativas museológicas. Diz a autora:

Sendo os museus históricos - informativos ou comemorativos - lugares de memória, são por natureza do campo da memória, não da história. Em outras palavras, nasceram reféns da memória. A crítica, já existente em muitos museus da Resistência, encontra aí seus limites. Ela se realiza plenamente quando faz dos museus objeto da história. (p.97)

Justifica-se, assim, a relevância do estudo materializado no livro da autora. O museu possui a dupla função comemorativa e informativa. Precisa produzir conhecimento e provocar emoção. Em nome disso, escolhas são feitas, e silenciamentos promovidos sem muito pudor. A vocação maior do museu é a celebração, e não a crítica. Daí a escolha dos temas da perseguição e da deportação, mesmo que não tenham por muitas vezes sido a motivação primeira dos movimentos da Resistência celebrados no espaço museológico. Daí a renovação historiográfica que acompanha os estudos sobre o período desde a década de 1970 ser incorporada timidamente naqueles espaços de memória. Daí a potência de um discurso que valoriza um coletivo imaginado: nós resistentes enfrentamos ele (indivíduo) colaborador.

O terceiro capítulo dedica-se à análise da escrita epistolar numa situação extrema: indivíduos que, resistentes ou reféns, receberam o aviso de que seriam fuzilados. Diante da certeza da morte, dentro de poucas horas, vinha a última missão de resumir uma trajetória e enviar a última mensagem aos entes queridos em algumas linhas. O número de indivíduos que passou por essa experiência não foi desprezível: cerca de 4.020 pessoas (p.172).

Denise Rollemberg esmiúça a morfologia de um conjunto de centenas dessas cartas e observa que, da situação-limite nasce uma escrita-limite (p.182). Os autores, provenientes dos mais distintos grupos sociais, regiões e convicções políticas e religiosas recorrem, muitas vezes, a temáticas e argumentos semelhantes quando estão a se despedir da vida. Em geral, parece que prevalece a ideia do "bem morrer": uma postura de tranquilidade em relação ao final de suas trajetórias. Claro que a autora leva em consideração que as cartas possuem o objetivo de tranquilizar parentes e companheiros, e por isso imprimir um tom de serenidade 
pode ser importante para aquelas pessoas. Além disso, não se pode desprezar que essas cartas passaram pela censura (seja alemã, seja francesa) antes de chegar aos destinatários. Outras que contivessem informações consideradas problemáticas jamais conheceriam o seu destino.

Outros apontamentos são dignos de menção. Reforçando a ideia presente no primeiro capítulo sobre a clivagem entre história e memória, ela observa que, no íntimo, o judaísmo não é a força motriz desses indivíduos. São raras as menções à rotina judaica, ainda que o elo com valores cristãos seja bastante presente (p.189). Isso, aliás, é um argumento interessante da autora, que observa a prevalência dos valores da família, religião e tradição nas cartas. Ora, a tríade é bastante próxima do lema da França de Vichy: trabalho, família, pátria (p.199). A ela, parece então que os valores dos condenados são bastante conservadores, ao ponto de se confundirem com aqueles dos colaboracionistas.

Se algo parece revolucionário à autora, é na questão dos condenados com suas esposas. Mesmo diante da pressão de uma sociedade católica e conservadora, quase sempre sugeriam que suas mulheres buscassem a felicidade em novos relacionamentos. Isso, talvez, esteja de acordo com aquilo que subjaz a esse tipo de escrita: as cartas de despedida são, no limite, cartas para si. São expressões da imagem que aquelas pessoas queriam deixar para a posteridade, como gostariam que fossem lembrados. É, de alguma forma, a curadoria de uma memória individual.

A Parte II do livro analisa o caso italiano. No capítulo 4, Rollemberg estuda dezesseis museus e suas construções memorialísticas. Convencionou-se no discurso museológico que a resistência no país teria início em 8 de setembro de 1943, quando do armistício italiano. Esses museus escrevem uma história da Itália até abril de 1945, quando termina a ocupação estrangeira do país. A escolha narrativa, então, fica clara: trata-se do combate contra a Alemanha, e não ao fascismo de Mussolini, que demandaria um recuo temporal maior. Dessa forma, também elencam indivíduos do partido fascista como heróis da Resistência nos museus e memoriais.

Ao mesmo tempo, há um sutil deslocamento temporal do antifascismo na Itália, como se ele fosse dominante desde a década de 1930, e não somente após a crise do regime de Mussolini depois de 1940. O esforço de silenciar o passado fascista é bem claro. É por isso, também, que os museus italianos, diferente dos franceses, apostam mais nas histórias locais em suas representações. É mais um artifício para afastar-se do coletivo, uma vez que o governo italiano era fascista ao início do conflito.

O caso mais curioso destacado pela autora nesse capítulo é o da Piazzale Loreto, em Milão, onde ocorreu a famosa efeméride na qual os corpos de Mussolini, sua amante Clara 
Petacci e outros fascistas foram pendurados num posto de gasolina e ficaram expostos para a população local. Da cena, restam pouco mais que vestígios. O posto não está lá, o matagal cobre o memorial existente no local... O passado embaraçoso foi sendo recalcado, e tentou-se imprimir, a partir da Resistência, a visão oposta, a do júbilo pela morte gloriosa, diretamente associada ao martírio cristão.

O capítulo final discorre sobre uma das grandes histórias da resistência italiana, a dos Sette Fratelli. Na região da Emilia-Romagna, em 28 de dezembro de 1943, sete irmãos, trabalhadores rurais, foram fuzilados. Faziam parte de uma família que, ali, fazia oposição ferrenha ao regime fascista (o irmão mais velho era do Partido Comunista) e, quando da Ocupação, auxiliava em ações clandestinas para proteger outros membros da oposição ao regime. Centenas de estrangeiros passaram pela fazenda da família e encontraram abrigo e proteção. Não poderia haver narrativa mais conveniente a um esforço de memória sobre a Resistência.

A autora destaca a potência dessa história familiar aos esforços de memória, e mapeia as variações narrativas sofridas pela mesma. $\mathrm{O}$ cortejo dos corpos, acompanhado por uma multidão, ganhou status de celebração da liberdade somente quatro anos depois de ocorrido. E foi em 1953, quando Ítalo Calvino escreveu dois textos sobre o acontecido - o que por si só já é uma amostra do alcance da história - ela parece se estabelecer no imaginário social, inspirando outras obras literárias, pinturas e o cinema, através de documentários e um filme. A casa da família, naturalmente, tornou-se um museu. Aqui, não parece haver espaço para a historiografia. Calvino comete um equívoco (intencional ou não), situando a formação do grupo resistente após o armistício e não no contexto anterior, quando de fato ocorreu, e é essa narrativa que se cristaliza. Uma vez mais, como diz Rollemberg, "a memória inventa o passado" (p.345).

Resistência parece cumprir uma dupla função no debate acadêmico brasileiro. Por um lado, é mais um expoente da hoje consolidada discussão acerca das relações entre história e memória, presente em parte relevante de teses e dissertações produzidas nos últimos anos. Traz à cena uma bibliografia mais ampla sobre um debate que nos tem sido tão caro. Ao mesmo tempo, esse panorama conceitual e metodológico propicia novas visões sobre os fascismos e sobre a guerra, que devem ser levadas em conta em novas publicações sobre o tema. 